\title{
STABILITY OF RUBBLE MOUND BREAKWATERS AGAINST SOLITARY WAVES
}

\author{
Miguel Esteban ${ }^{1}$, Izumi Morikubo ${ }^{2}$, Tomoya Shibayama ${ }^{3}$, Rafael Aranguiz Muñoz ${ }^{4}$, Takahito \\ Mikami $^{5}$, Nguyen Danh Thao ${ }^{6}$, Koichiro Ohira ${ }^{7}$ and Akira Ohtani ${ }^{8}$ \\ No formulas currently exist to design armour units against tsunami attack. To develop such formulae, laboratory \\ experiments were carried out to clarify the failure mechanism of these types of structures. Also, the behavior of \\ armour units against real cases of tsunami attack during the 2011 Tohoku tsunami were evaluated. Both the results of \\ the laboratory experiments and the breakwaters studied in the field where then analyzed in terms of well established \\ formulas such as that of Van der Meer or Hudson. The design of structures that only fail partially during a given \\ tsunami event ("resilient" or "tenacious" structures) should be prioritized in future counter-measures, and in order to \\ make it possible to construct such structures a modification of the Hudson formula for their design is proposed.
}

Keywords: rubble-mound breakwater; solitary waves; tsunami; Tohoku; stability; Hudson; Van der Meer

\section{INTRODUCTION}

On March 11, 2011, a large earthquake of magnitude 9.0 on the Richter scale occurred offshore the northeast coast of Japan, generating a major tsunami that devastated large parts of Japan's north-eastern coastline. This "Great Eastern Japan Earthquake and Tsunami" has been described as one in several thousand years event, and was one of the worst tsunamis that affected Japan since records began. In its aftermath the reliability of the different available tsunami counter-measures is being re-assessed, with important questions being asked about the ability of hard measures to protect against them. A variety of failure mechanisms have been reported for different types of structures (Mikami et al., 2012). Generally speaking, composite breakwaters (those protected by armour units such as tetrapods) were more resilient than simple caisson breakwaters. It appears that the armour was effective at dissipating the brunt of the tsunami wave forces on the seaward side of the caisson, although damage to armour units was also recorded for several breakwaters in the Tohoku area (see Fig. 1). For some of these breakwaters, armour units of different sizes and types were used in the same breakwater, and it appears that damage is dependent on the weight of the units (as can be expected from formulas such as that of Van der Meer, 1987). The most important question at this point, however, is whether any such armoured structures should be given preference when designing tsunami counter-measures, and whether these counter-measures should be attempted at all.

To date, a certain amount of work has been carried out on the design of dykes and vertical structures against wind waves, including assessments of the reliability of these structures such as in Esteban et al. 2007. For the case of solitary waves, Tanimoto et al. (1984) performed large-scale experiments on a vertical breakwater by using a sine wave and developed a formula for the calculation of the wave pressure. Ikeno et al (2001) conducted model experiments on bore type tsunamis and modified Tanimoto's formula by introducing an extra coefficient for wave breaking. Subsequently Ikeno et al (2003) improved the formula to include larger pressures around the still water level, where the largest wave pressure was observed to occur. Mizutani and Imamura (2002) also conducted model experiments on a bore overflowing a dike on a level bed and proposed a set of formulae to calculate the maximum wave pressure behind the dike. Esteban et al. (2008) calculated the deformation of the rubble mound foundation against different types of solitary waves, allowing for the determination of the caisson tilt. However, both for the case of tsunami and wind waves, all the methods outlined above deal with simple type caisson structures or dykes. However, many composite structures exist, where a caisson breakwater is protected by armour on its seaside part. To this effect Esteban et al. (2009) calculated the effect that a partially failure armour layer would have on the forces exerted by a solitary wave on a caisson, allowing for the determination of the caisson tilt. However, to the authors' knowledge, no formula has yet been derived for the design of armour units against tsunami attack, and

\footnotetext{
${ }^{1}$ Dept. Civil and Environmental Engineering, Waseda University, 3-4-1 Ookubo, Tokyo, 169-8555, Japan.

${ }^{2}$ Nihon Unisys. Ltd., Tokyo, Japan

${ }^{3}$ Dept. Civil and Environmental Engineering, Waseda University, 3-4-1 Ookubo, Tokyo, 169-8555, Japan.

${ }^{4}$ Dept. Civil Engineering, Universidad Catolica de la Ssma Concepcion, Concepcion, Chile

${ }^{5}$ Dept. Civil and Environmental Engineering, Waseda University, 3-4-1 Ookubo, Tokyo, 169-8555, Japan.

${ }^{6}$ Dept. Civil Engineering, Ho Chi Minh City University of Technology, Ho Chi Minh, Vietnam

${ }^{7}$ Chubu Electric Power Company, Japan

${ }^{8}$ Ministry of Land, Infrastructure, Transport and Tourisim, Tokyo, Japan
} 
hence it would be difficult for a practicing engineer to take this into account during design. Although many of these structures are designed primarily against storm waves, it is necessary to develop a design methodology that ensures that these structures do not fail catastrophically under a tsunami event, and that they can provide some protection to the local community.

\section{FIELD SURVEYS}

The authors conducted field surveys as a part of the larger 2011 Tohoku Earthquake Tsunami Joint Survey Group in Iwate, Miyagi, Fukushima, Ibaraki and Chiba prefectures (Mori et al., 2012). During these surveys detailed reports of the failure of armour layer at various breakwater locations along the affected coastline were made. Two of these were composite breakwaters, those at Hikado and Ooya ports (see Fig. 1 and 2), located close to Kesennuma City. Both of these breakwaters protect small fishing ports and the villages behind them, which nevertheless suffered major damage due to the tsunami.

These two breakwaters are situated fairly close to each other and are facing the open sea, meaning that the tsunami waves would have attacked them directly. Three different measurements of wave heights were taken in this area, $15.7 \mathrm{~m}$ (by the authors themselves) and 16.55 and $15 \mathrm{~m}$ (by other members of the Tohoku Earthquake Tsunami Joint Survey Group). In the present analysis the authors have thus adopted their own value of $15.7 \mathrm{~m}$ for the tsunami height at the breakwater, as it sits roughly half way between the two values measured by the other teams.

Three different types of armour units were present at the breakwaters surveyed. Ooya port is made of Sea-Locks, and Hikado port has both X-block and Hollow Pyramid units along the breakwater (Xblocks in the body of the breakwater and heavier Hollow Pyramids at the head). The X-blocks and SeaLocks armour completely failed: the armour units were scattered over a wide area in front of the breakwater, with only the top of some of the units still showing above the water surface. The exact failure mechanism is unclear, and whether the units were displaced by the incoming or the outgoing wave could not be easily established. In any case, the breakwater was overtopped with the whole area being completely underwater at one point during the tsunami attack (which would have also generated large underwater currents around the structure). It is interesting to note that the caisson breakwaters that were situated behind the armour units did not suffer any damage, which further adds to the uncertainties regarding the role of the armour units in enhancing or minimizing the damage to the caissons behind them.

A summary of these units can be found in Table 1 (along other typical armour units shown for comparison). The table also shows the Hudson Damage Coefficients $\left(K_{D}\right)$ that were used for each of these armour units in the analysis.

\begin{tabular}{|c|c|c|}
\hline \multicolumn{2}{|c|}{ Table 1. Summary of armour units surveyed } \\
\hline Unit & Approximate Weight & $K_{D}$ \\
\hline Sea-Lock & 3.2 tons & 10 \\
\hline X-Block & 5.76 tons & 8 \\
\hline Hollow Pyramid & 28.8 tons & 10 \\
\hline Rock & N/A & 4 \\
\hline Tetrapods & N/A & 8 \\
\hline Tribar & N/A & 10 \\
\hline Modified Cube & N/A & 7.5 \\
\hline
\end{tabular}




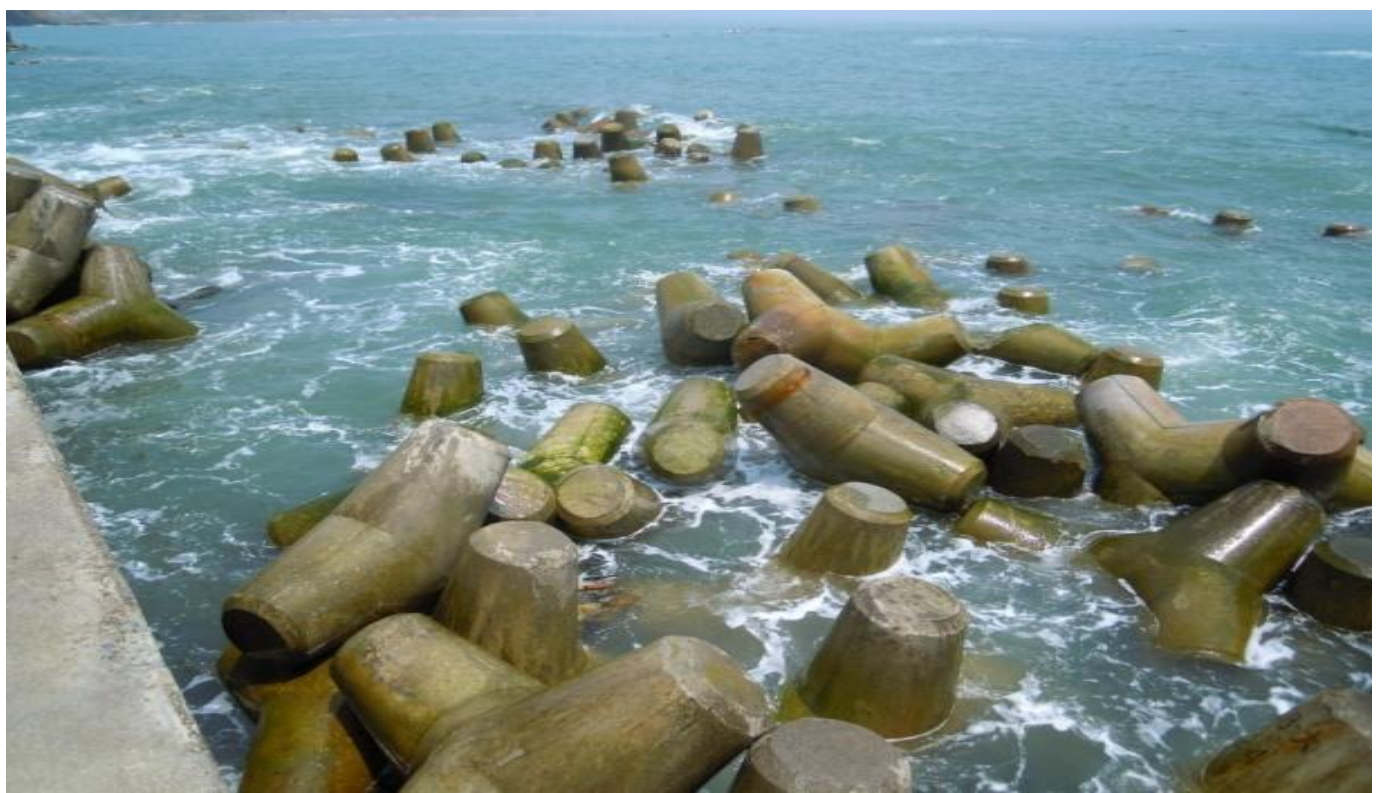

Figure 1. Damaged Sea-Block Armour Units at Ooya Port

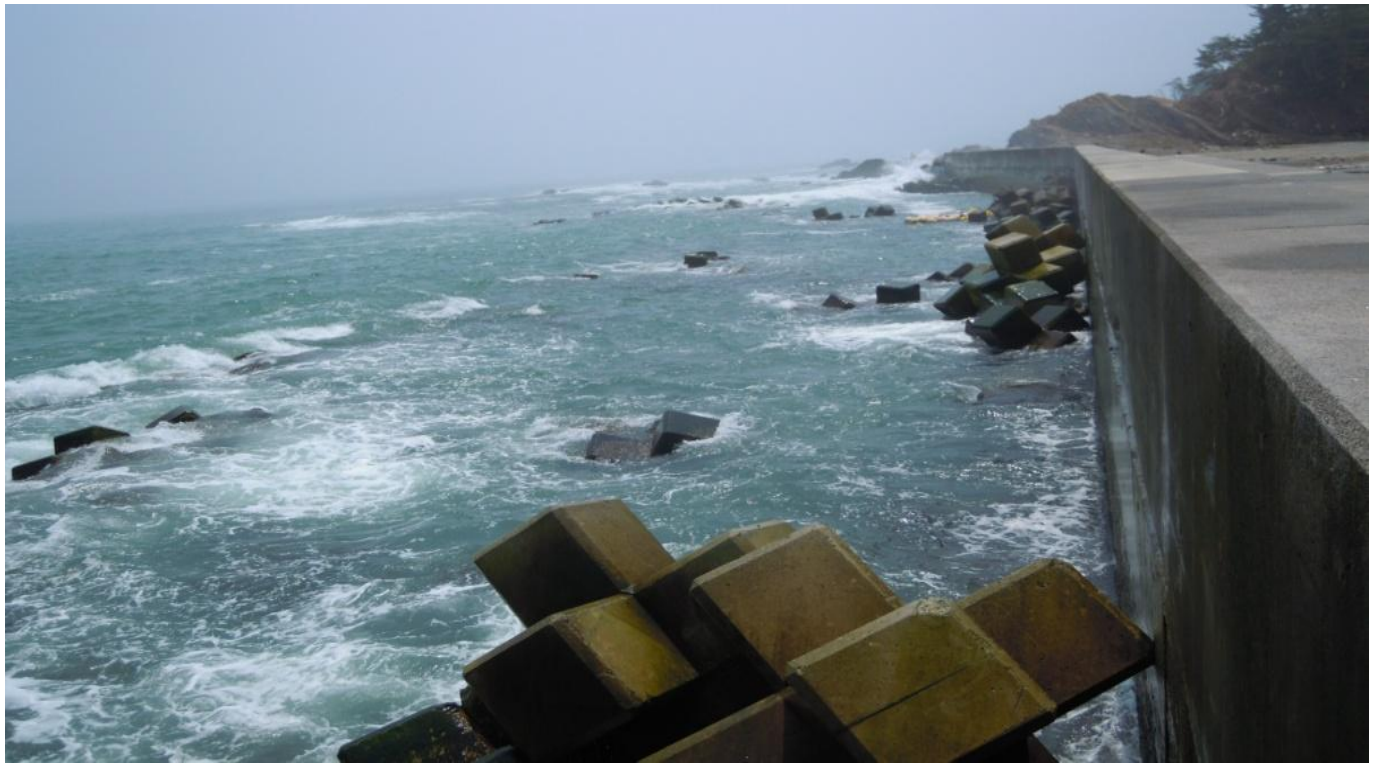

Figure 2. Failed X-Block Armour Units at Hikado Port

\section{LABORATORY EXPERIMENTS}

Laboratory experiments were carried out using solitary waves generated by a wave paddle in a wave flume at Waseda University in Japan (dimension $14 \mathrm{~m}$ long, $0.6 \mathrm{~m}$ high, $0.41 \mathrm{~m}$ wide). The experimental layout used is shown in Fig. 3. On one side of the tank a caisson breakwater was placed, which was protected by an armour layer made up of stones of different sizes (a total of 3 different stone sizes were used, with median weights $W$ of $27.5,32.5$ and $37.5 \mathrm{~g}$ ) to test the sensitivity of armour weight on breakwater damage, as shown in Fig. 4. Two different breakwater configurations were also tested (with a seaward angle $\alpha$ of 30 and $45^{\circ}$ ). Each of the breakwater configurations was also tested for three different water depths, $h=17.5,20$ and $22.5 \mathrm{~cm}$. The number of armour units extracted after one solitary wave was counted with the aid of a high-speed photographic camera, and each of the experimental conditions was repeated 10 or 15 times to ensure accurate results. A summary of all the experimental conditions that were considered is shown in Table 2. 
The wave profile was measured using two wave gauges, one located approximately in the middle of the tank and the other one just before the breakwater (in order to measure the incident wave height). The solitary waves that were used were thus measured to have a half-period $T / 2=3.8 \mathrm{sec}$. As the experiments were carried out in a 1/100 scale, this would represent a $T=76 \mathrm{sec}$ wave in the real world (using Froude Scaling). The waves generated were $8.4 \mathrm{~cm}$ in height, thus corresponding to $8.4 \mathrm{~m}$. The wave profile for one typical wave, as recorded by the measuring software, is shown in Fig. 5. The height $H$ of the wave was identical in all experiments, as the input given to the wave paddle were not changed between experiments.

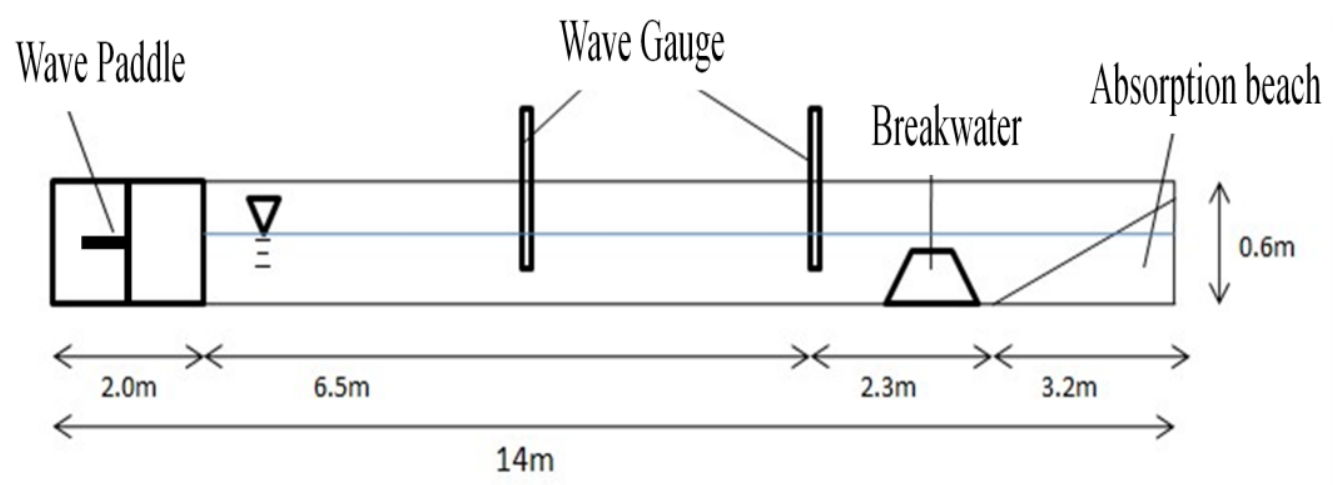

Figure 3. Experimental set-up

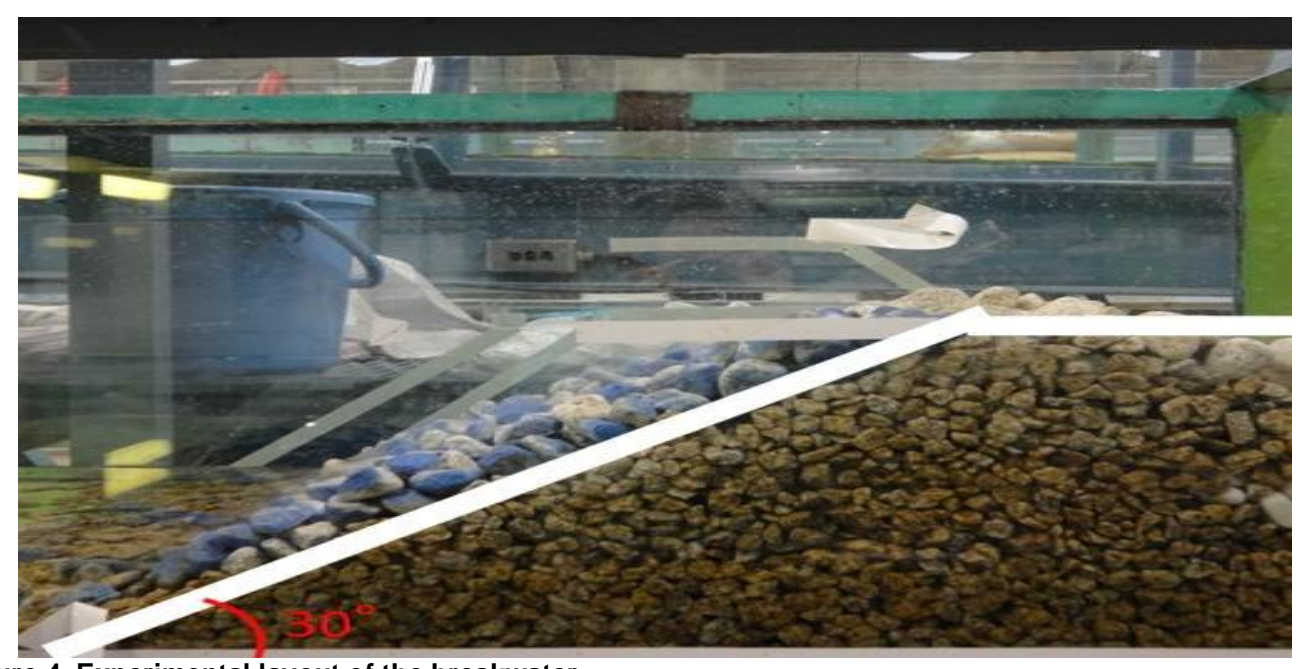

Figure 4. Experimental layout of the breakwater

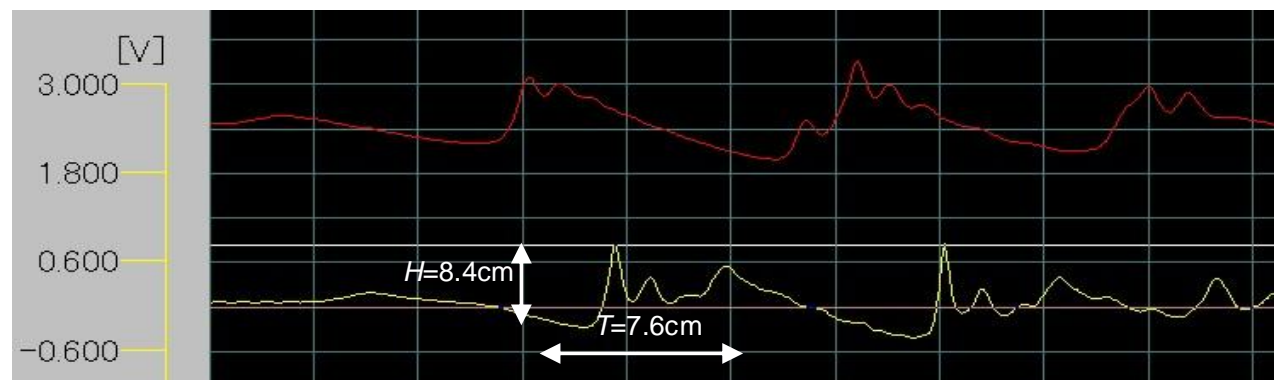

Figure 5. Wave profile. Top graph shows the profile at the middle of the tank, bottom graph shows the incident wave profile. 


\begin{tabular}{|c|c|c|c|}
\hline $\begin{array}{l}\text { Structure } \\
\text { Angle } \\
(\alpha)\end{array}$ & $\begin{array}{l}\text { Weight } \\
\text { of the } \\
\text { stone } \\
\text { (W) }\end{array}$ & $\begin{array}{l}\text { Water } \\
\text { depth } \\
\text { (h) }\end{array}$ & $\begin{array}{l}\text { Number of } \\
\text { experiments }\end{array}$ \\
\hline $30^{\circ}$ & $27.5 \mathrm{~g}$ & $17.5 \mathrm{~cm}$ & - \\
\hline $30^{\circ}$ & $27.5 \mathrm{~g}$ & $20 \mathrm{~cm}$ & - \\
\hline $30^{\circ}$ & $27.5 \mathrm{~g}$ & $22.5 \mathrm{~cm}$ & - \\
\hline $30^{\circ}$ & $32.5 \mathrm{~g}$ & $17.5 \mathrm{~cm}$ & $\times 15$ \\
\hline $30^{\circ}$ & $32.5 \mathrm{~g}$ & $20 \mathrm{~cm}$ & $\times 15$ \\
\hline $30^{\circ}$ & $32.5 \mathrm{~g}$ & $22.5 \mathrm{~cm}$ & $\times 15$ \\
\hline $30^{\circ}$ & $37.5 \mathrm{~g}$ & $17.5 \mathrm{~cm}$ & $\times 15$ \\
\hline $30^{\circ}$ & $37.5 \mathrm{~g}$ & $20 \mathrm{~cm}$ & $\times 15$ \\
\hline $30^{\circ}$ & $37.5 \mathrm{~g}$ & $22.5 \mathrm{~cm}$ & $\times 15$ \\
\hline $45^{\circ}$ & $27.5 \mathrm{~g}$ & $17.5 \mathrm{~cm}$ & $\times 15$ \\
\hline $45^{\circ}$ & $27.5 \mathrm{~g}$ & $20 \mathrm{~cm}$ & $\times 15$ \\
\hline $45^{\circ}$ & $27.5 \mathrm{~g}$ & $22.5 \mathrm{~cm}$ & $\times 15$ \\
\hline $45^{\circ}$ & $32.5 \mathrm{~g}$ & $17.5 \mathrm{~cm}$ & $\times 15$ \\
\hline $45^{\circ}$ & $32.5 \mathrm{~g}$ & $20 \mathrm{~cm}$ & $\times 15$ \\
\hline $45^{\circ}$ & $32.5 \mathrm{~g}$ & $22.5 \mathrm{~cm}$ & $\times 15$ \\
\hline $45^{\circ}$ & $37.5 \mathrm{~g}$ & $17.5 \mathrm{~cm}$ & $\times 10$ \\
\hline $45^{\circ}$ & $37.5 \mathrm{~g}$ & $20 \mathrm{~cm}$ & $\times 10$ \\
\hline $45^{\circ}$ & $37.5 \mathrm{~g}$ & $22.5 \mathrm{~cm}$ & $\times 10$ \\
\hline
\end{tabular}

\section{RESULTS}

Figs. 6 and 7 show the average number of armour units extracted from the breakwater for each of the breakwater armour unit weighs and depths of water, for $\alpha=45^{\circ}$ and $\alpha=30^{\circ}$, respectively. The vertical axis gives the number of experiments for which a certain number of armour units were removed, and thus this figure represents a probability distribution function. However, due to time constraints each experimental condition could only be reproduced 15 times, and thus it is difficult to clearly see the characteristic bell-shape of these distributions. Hence, the average number of removed armour units for each experimental condition was used in the analysis of the results.

Generally damage to the $45^{\circ}$ structure was far greater than to the $30^{\circ}$, as expected. No pattern of damage could be clearly observed from the depth of water in front of the structure, and indeed the wave profile did not appear to significantly change between them (which always looked like a solitary wave). This is different from the results of Esteban et al. (2009) which found that different types of waves could be generated for different depths (bore-type, breaking and solitary type waves). However, in the present experiments the depth of water did not change enough between each experimental condition to result in significant differences in the wave profile. 


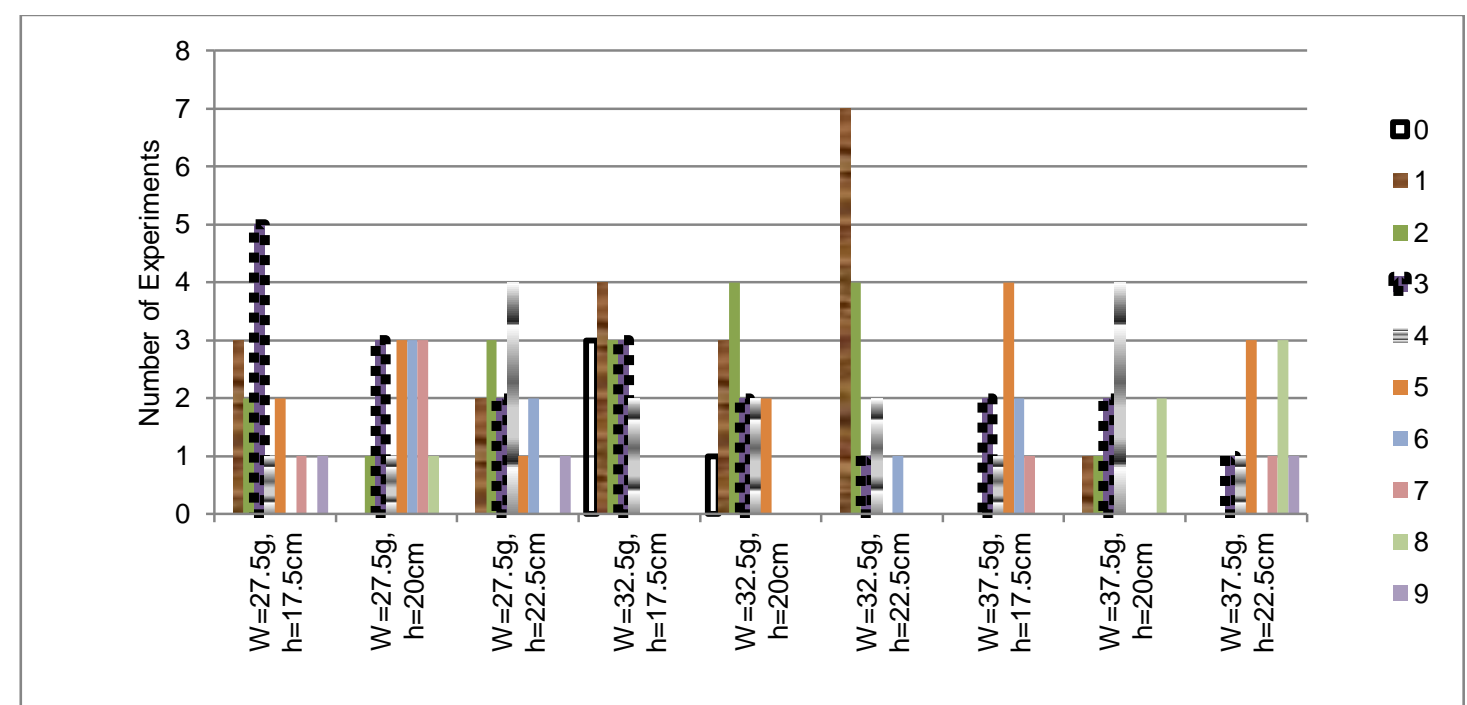

Figure 6. Number of armour units moved for each of the experimental conditions, for $\alpha=45$

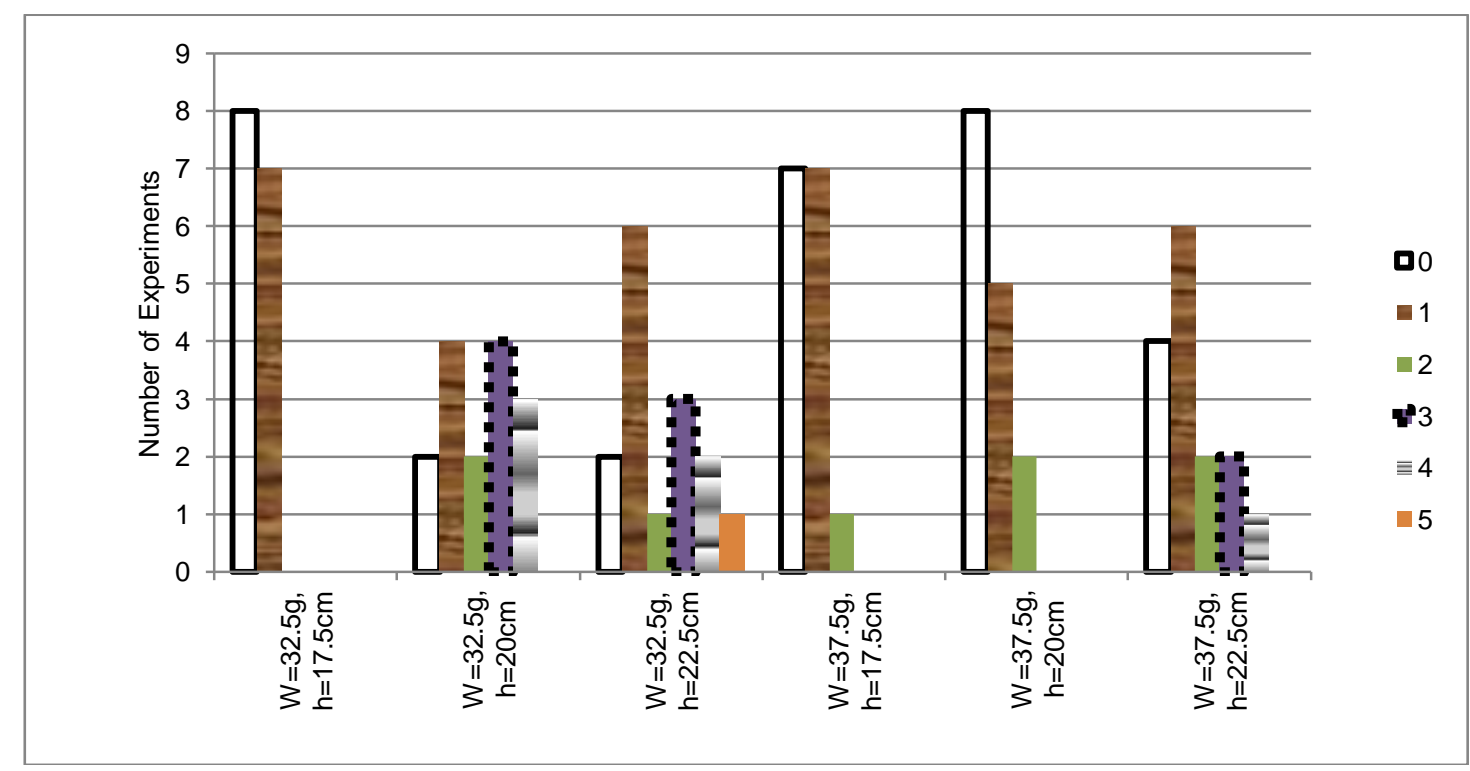

Figure 7. Number of armour units moved for each of the experimental conditions, for $\alpha=30$

\section{ANALYSIS}

According to the experimental results an armour damage parameter $S$ similar to that used in Van der Meer (1987) was obtained for each of the breakwater configurations. This armour damage parameter $S$ is defined as

$$
S=\frac{A_{e}}{D_{n 50}^{2}}
$$

where $A_{e}$ is the erosion area of the breakwater profile between the still water plus or minus one wave height, and $D_{n 50}$ is the mean diameter of the armour stones.

The values of $S$ obtained from the experiments were compared with the theoretical values that would have been obtained using Van der Meer's equation, using only one wave $(N=1)$. Van der Meer's equation divides waves into plunging or surfing depending on their surf similarity parameter, $\xi_{\mathrm{m}}$,

$$
\xi_{m}=\tan \alpha / \sqrt{2 \pi H_{s} / g_{1} T_{m}^{2}}
$$


where $\alpha$ is the angle of the front slope of the structure with respect to the horizontal, $H s$ is the significant wave height, $g$ is the acceleration of gravity and $T_{m}$ is the wave period

According to this expression waves can be classified into two different types, plunging and surging. The transition between one and the other takes place at a critical value of $\xi_{\mathrm{m}}$, which can be referred to as $\xi_{\mathrm{o}}$,

$$
\xi_{0}=\left(6.2 P^{0.31} \sqrt{\tan \alpha}\right)^{1 / P+0.5}
$$

where $P$ is the overall permeability of the breakwater.

Thus, for plunging breakers the required diameter of the armour stones, $D_{n 50}$, can be found from the following expression,

$$
\frac{H_{S}}{\Delta D_{n 50}} \sqrt{\xi_{m}}=6.2 P^{0.18}\left(\frac{S}{\sqrt{N}}\right)^{0.2}: \xi_{m 0}<\xi_{c}
$$

For surging breakers,

$$
\frac{H_{S}}{\Delta D_{n 50}}=1.0 P^{-0.13}\left(\frac{S}{\sqrt{N}}\right)^{0.2} \sqrt{\cot \alpha} \xi_{m b} P: \xi_{m}>\xi_{\mathrm{c}}
$$

The theoretical values of $S$ compared to those obtained in the laboratory experiments for each experimental condition are shown in Figs. 8-12. It is important to understand that the Van der Meer formula was not originally intended to be applied to solitary waves, and hence using it in this way is questionable. The $N$ value for the present case is 1 , and it is clear that using such a value was clearly not the way the formula was intended to be applied. Nevertheless, the use of this formula gives good results, especially for the case were $\alpha=30^{\circ}$. It should also be noted that $\alpha=45^{\circ}$ is outside the range of application of the Van der Meer formula, as breakwaters are not normally designed with such a steep gradient, as they are generally considered to be quite unstable in this condition. The results of the present experiments also show that for the case of tsunamis this configuration of $\alpha=45^{\circ}$ is far more unstable than under a more mild slope such as $\alpha=30^{\circ}$.

Although the Van der Meer formula appears to give good results for $\alpha$ values that are within its range of application, an inherent problem exists in that it is necessary to know $T_{m}$ and the $P$ of the breakwater in order to apply it correctly. For the case of the laboratory experiments these can be accurately measured, though for the case of analysing the real case failure of the units at the ports investigated during the field trips it is considerably harder, not least because of the lack of available data. Although assumptions can be made with respect to these values, the authors chose to follow the simpler method of using the Hudson formula (CERC, 1984),

$$
W=\frac{\gamma H_{S}}{K_{D}\left(S_{r}-1\right)^{3} \cos \alpha}
$$

where $\gamma$ : density of armour (tonnes/ $\mathrm{m}^{3}$ ), $S r$ : Relative underwater density of armour and $K_{D}$ is an empirically determined damage coefficient

Unlike Van der Meer's formula, the Hudson formula does not provide an indication of the degree of damage that can be expected. However, the ultimate objective of the present work is to attempt to quantify how resilient each structure is, so that structures are designed in a way were they can partially fail against a certain tsunami height, yet continue to provide some protection after the event.

The damage to each section of the armour-protected structures that were recorded during the various field trips and the results obtained in the lab were thus interpreted using a damage factor $S$, as defined by Van der Meer (1988). In order to compare how well the results of the present experiments compared with the field data, the ratio $R$ of the actual weight of armour $W$ that would be required according to the Hudson formula over the actual weight of the armour at the two breakwaters in the field and the experimental results was plotted versus the recorded values of $S$ in Fig. 13.

$$
R=\frac{W_{\text {actual }}}{W_{\text {required }}}
$$


This figure shows the results for each of the types of armour units and how those that have lower values of $R$ failed completely (represented by $S$ values of 15) whereas those units with higher values of $\mathrm{R}$ did not fail catastrophically. However, it is important to understand also that the field results represent breakwaters that were overtopped whereas those in the laboratory were not, and hence it is not clear that both results are comparable.

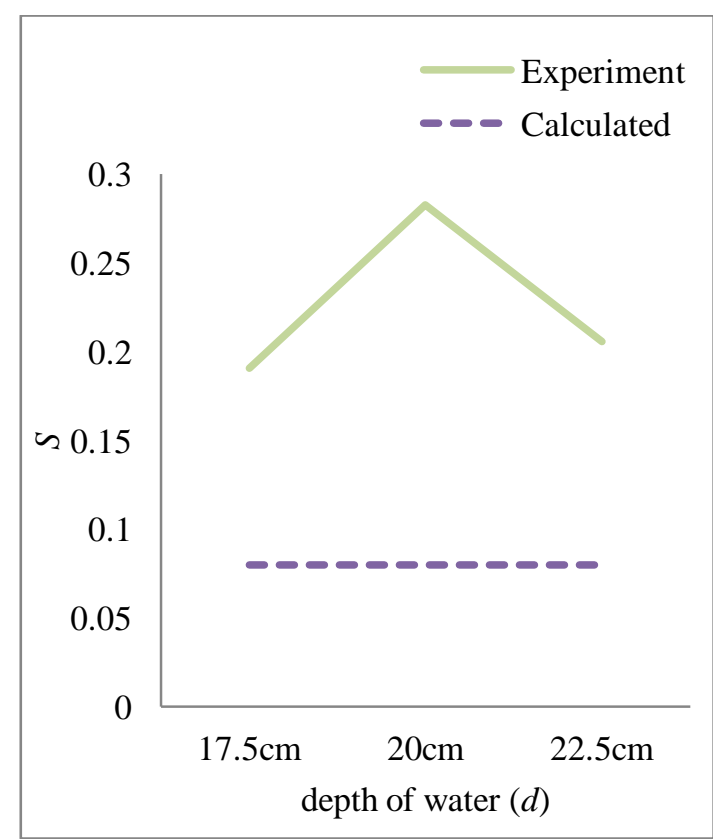

Figure 8. Exp. and calculated $S, \alpha=45^{\circ}$ and $W=27.5 \mathrm{~g}$

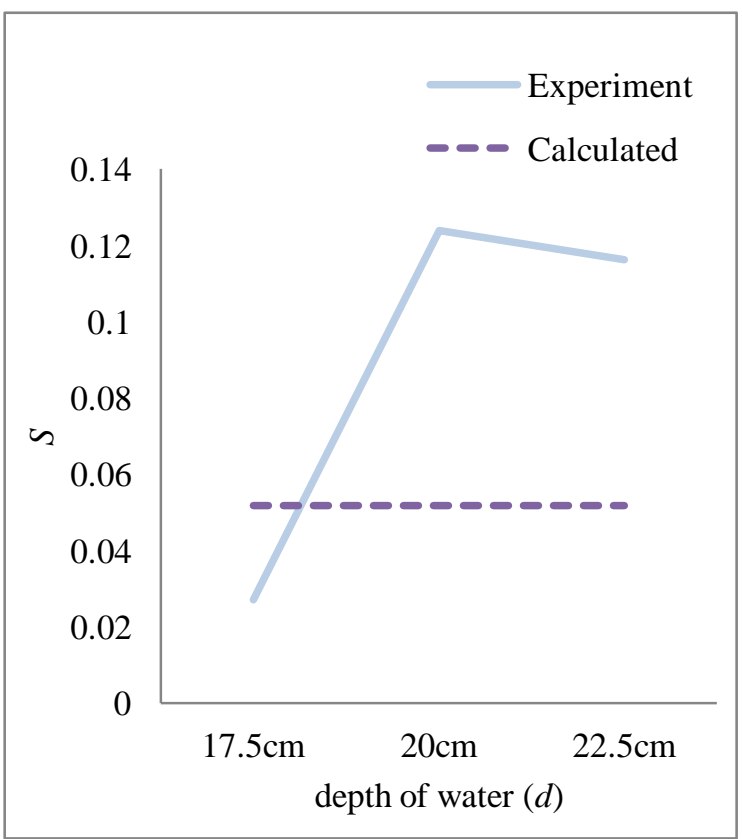

Figure 9. Exp. and calculated $S, \alpha=30^{\circ}$ and $W=32.5$

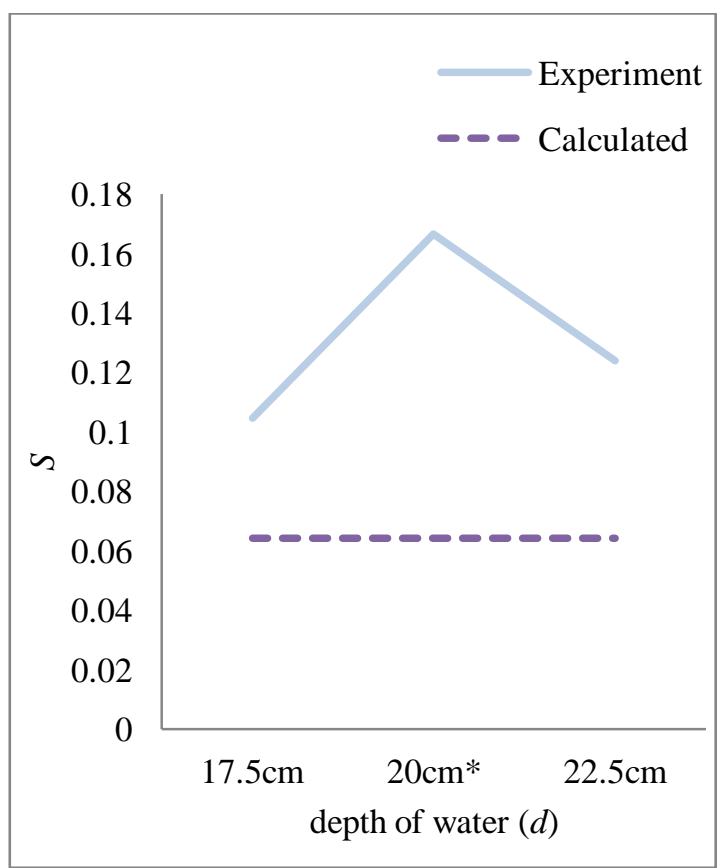

Figure 10. Exp. and calculated $S, \alpha=45^{\circ}$ and $W=32.5 \mathrm{~g}$

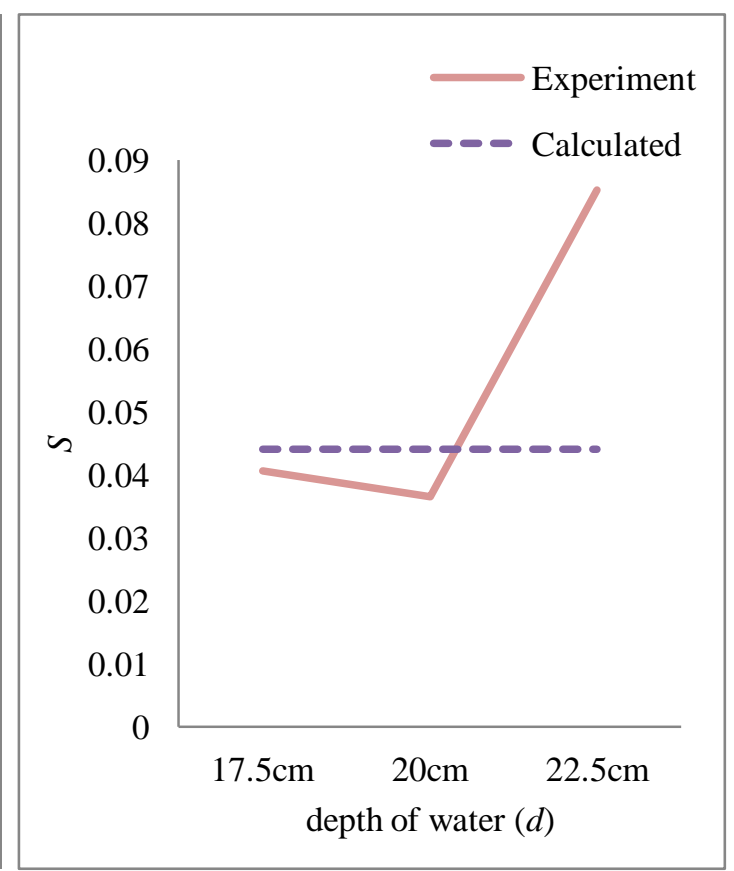

Figure 11. Exp. and calculated $S, \alpha=30^{\circ}$ and $W=37.5$ 


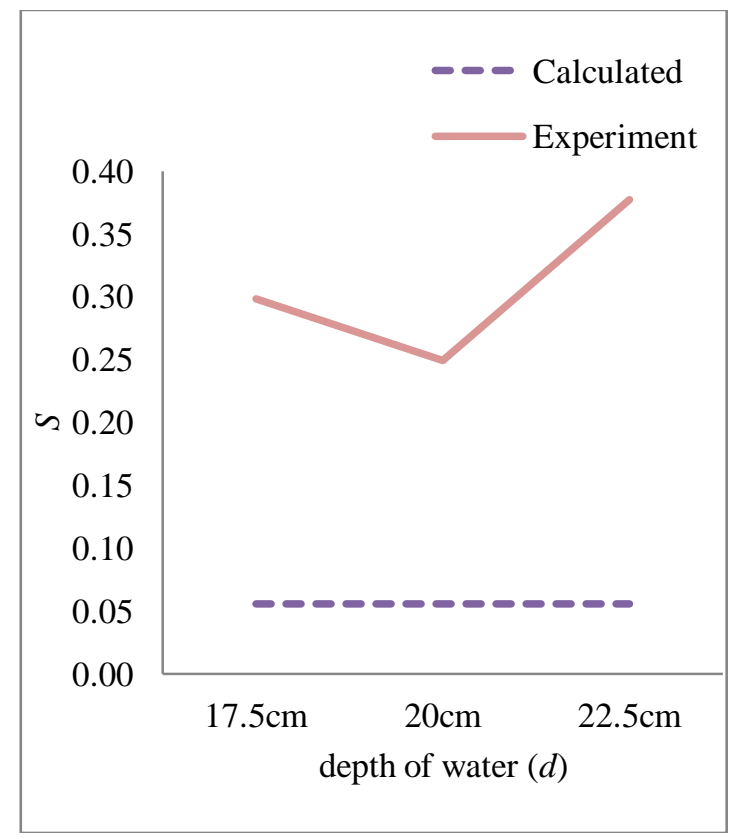

Figure 12. Exp. and calculated $S, \alpha=45^{\circ}$ and $W=37.5 \mathrm{~g}$

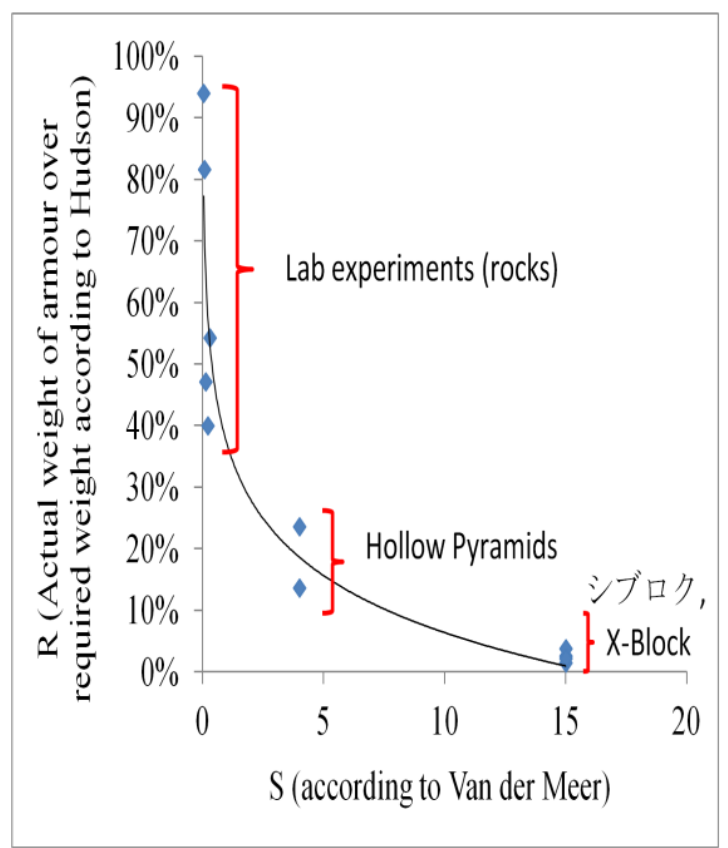

Figure 13 Plot of the actual over required Weight of armour and $S$

\section{TSUNAMI LEVELS AND THEIR INFLUENCE ON DESIGN}

Following the Great Eastern Japan Earthquake and Tsunami of 2011 the Japanese Coastal Engineering Community have started to classify tsunami events into two different levels, according to their level of severity and intensity'

- Level 1 Events. Which would represent events with a return period of several decades to $100+$ years -literally the Japanese expression which has been used in coastal engineering discussions would translate as a return period from 50-60 to 150-160 years. These tsunamis would be relatively low in height, typically less than $7-10 \mathrm{~m}$.

- Level 2 Events. These would be less frequent events, typically taking place between every few hundred to a few thousand years. The tsunami inundation heights would be much bigger, typically over $10 \mathrm{mt}$, but would encompass events of up to $20-30 \mathrm{~m}$ in height. It is clear that both the 2004 Indian Ocean and 2011 Great Eastern Japan Earthquake and Tsunami would fall within this category.

The way to defend against each level of tsunami would be different. So-called "hard measures" such as breakwaters or dykes should be strong enough to protect against the loss of life and property for a level 1 event. However, the construction of such measures against level 2 events is often seen as unrealistic from a cost-benefit point of view. Thus, during these events it would be accepted that hard measures would be overcome and the protection of the lives of residents would rely on "soft measures", such as evacuation plans and Evacuation buildings. Nevertheless, hard measures would also have a secondary role to play in delaying the incoming wave and giving residents more time to escape.

Despite these hard measures being overcome by level 2 tsunamis, the construction of "resilient" structures should be pursued, so that these are allowed to only partially fail, and can either still fulfil their function after the event or be repaired quickly. It is thus necessary to develop a series of formulas that can allow the determination of the size or required armour units against different tsunami heights, as will be outlined in the next section.

\section{MODIFICATION OF THE HUDSON FORMULA FOR TSUNAMI EVENTS}

According to the results outlined in the previous sections, the authors developed a modification of the Hudson formula that could be employed for the design of armour units in tsunami prone areas. Thus, armour units would first be designed using the Van der Meer or Hudson formulas against wind 
waves present in the area, as usual in the design of any breakwater. However, at the end of the design procedure a check should be made that the breakwater meets the requirement of the two formulas below.

For level 1 events the armour should suffer little to no damage (i.e. an $S$ value of under 2) as the breakwater would have to resist not only the first wave of the tsunami but also subsequent waves, and thus it is imperative that the structure does not deform significantly, or that partial failure in the armour does not result in an amplification of wave forces (Esteban et al. 2009 showed how a partly failed armour layer can amplify the forces exerted by a solitary wave on the caisson of a composite breakwater). Thus, for level 1 events the following formula should be used:

$$
W=\frac{\gamma H_{\text {tsunami }}^{3}}{K_{D}\left(S_{r}-1\right)^{3} \cos \alpha}
$$

where $H_{\text {tsunami }}$ would be the wave height of the tsunami in metres, and which would of course be location specific.

However, for level 2 events some degree of failure is to be allowed. Thus, according to the results shown in Fig. 13, and accepting a $S=4$, the armour should fulfil the requirements given in the formula below:

$$
W=0.25 \frac{\gamma H_{\text {tsunami }}^{3}}{K_{D}\left(S_{r}-1\right)^{3} \cos \alpha}
$$

By using this formula there is no danger of the breakwater being greatly overdesigned for any particular area, as partial failure would be assumed to take place in the most severe cases of tsunami attack (i.e. level 2 events). Using Eq. 8 instead of Eq. 9 for level 2 events, however, would require for certain regions of the world (such as the Tohoku area) the construction of massive armour units that would only be required every few thousand years, clearly an unrealistic concept.

In this type of design it would be very important to analyse $H_{\text {tsunami }}$ correctly, and to do this a certain wave height should be chosen, corresponding to historical records of tsunamis in the area and to perceptions of accepted risk. For the case of Japan these are framed around this dual tsunami level classification, where for the highest tsunami inundation level that is believed can occur at a given place (for a return period of several thousand years) should be used for the level $2 H_{\text {tsunami }}$. Thus, depending on the specific area where a breakwater was to be designed and the tsunami risk in the region, the required $W$ of a breakwater would be ultimately determined by the wind wave conditions or by the tsunami risk.

\section{DISCUSION}

There are several problems when attempting to apply the Van der Meer formula to the present experiment. First, the formula does not explicitly consider the depth in front of the breakwater. This is a problem for the application to tsunamis, as the behaviour of the solitary wave as it approaches the reakwater will differ according to the water depth. Esteban et al. (2009) showed how according to the water depth the tsunami behaviour can be classified into 3 types:

- Almost breaking: as the incident wave approaches the breakwater it starts to deform prior to impact. If the wave breaks onto the breakwater directly, the load profile is characterised by a high initial peak followed by smaller subsequent oscillations.

- Breaking wave: the front of the solitary wave appears similar to a breaking wind wave, though the period of the wave is much longer and hence it differs due to the large amount of water at the back.

- Bore type: the wave breaks before it arrives at the breakwater. The wave front that arrives is characterised by a high turbulence, though due to this turbulence the impact component of the wave force is completely lost and thus mostly hydrostatic pressure is applied to the breakwater. Very little load is placed on the foundations by these waves, which would imply that breakwaters should be relatively safe against this type of wave attack.

For the case of the laboratory experiments carried out in the present work, only the "almost breaking" type was analysed. However, to what extent do these types of solitary wave experiments really represent a tsunami phenomenon is also not clear. Judging from video footage of the Tohoku 
2012 event, a tsunami event is a complex phenomenon, and one of the defining failure modes might be the overtopping effect of the wave. This prolonged overtopping effect would generate a very intense current, and many structures along the Tohoku coastline appeared to have failed due to erosion of the landside toe of the structure. This has lead some researchers (Kato et al., 2012, Sakakiyama, 2012) to state that the failure mode is directly related to this overtopping current. Nevertheless, the initial impact of the wave clearly also has an effect on the breakwater armour, and it would appear logical that once this initial wave shock has been absorbed, the overtopping current would probably have no effect on the armour units. This, however, should be checked in future laboratory experiments. Also, although ultimately the current might be the determining factor in the failure of the armour units, there is probably a clear relationship between the height of the wave and the velocity of the current. Establishing the exact current velocity for a given tsunami event is far more difficult than establishing the tsunami wave height (which can easily be measured through field surveys). Thus, the formulae proposed can be used as a proxy for the effect of the current, and thus be easily used by a practicing engineer in determining the required armour size.

The design of a composite or rubble mound breakwater in a tsunami zone is thus a complex process. Not only does the stability of the armour have to be checked against wind waves in the area, but the stability of the armour against tsunami should also be checked. Importantly, the landside part of the structure should also be checked for potential scour due to the wave as it starts to overtop. It should be noted that it is likely that most of the landside toe failure occurs during the initial overtopping, as once a large inundation height is established behind the breakwater the current would probably flow at a higher level, and thus scour would be less significant. Finally, the effect of the returning wave should also be checked, as this can result in the inverse process and lead to the destruction of many structures that survived the initial wave attack, as was evident in the Tohoku area.

Previously tsunami counter-measures in Japan had been designed to be higher than the expected tsunami wave height, though they were clearly under-designed for the 2011 Tohoku tsunami. Following this event there is a general perception that it is too difficult and expensive to design tsunami counter-measures against what have been defined as "level 2 events", though whatever structures exist must be designed to fail in a non-catastrophic way, even if their design criteria is exceeded. These were described by Kato (2012) as "tenacious structures", representing a structure that would slowly fail over the course of the event while retaining some functionality (this idea is similar to what has been described by other authors as "resilient" structures, which would indicate a structure that would suffer limited damage even if its design load was greatly exceeded). Such a difference between "tenacious" and normal structures could be seen in the failure of the breakwaters at Kamaishi (which could be regarded as a "tenacious structure", as it suffered great damage but somehow survived the event) and that at Ofunato (which was completely wiped out).

The present work concerned itself mainly with breakwaters, though it is also relevant to coastal dykes, as in Japan these are often protected by armour units on their seaside, either placed directly in front of the dyke or a few dozen metres in front of it (in the beach or just immediately in front of the beach). Currently, there is research going on in Japan on whether protection structures (such as dykes) should be reinforced in the future. Recommendations are thus being made on how to improve the resilience ("tenacity") of dykes, by improving their armouring or placing scour protection measures at their backside or at the toe of the structure (especially at the toe at the landside part of the structure).

Despite this, no formula has been developed in the past to design the armour of rubble mound breakwaters against tsunami attack. The question of whether to construct such structures to defend against a tsunami is controversial. Currently it is believed that such structures can protect property in the event of a level 1 event, though they will have little effect for the case of a level 2 event. The erection of vertical barriers and dykes, however, can clearly give extra time for residents to escape, as seen by footage of videos during the disaster. Although these barriers can be ultimately destroyed by a level 2 event, it is unclear how much extra protection the armour units would provide, and whether it would be preferable to just create a wider concrete barrier. Much is still not understood about the failure of protective measures in the event of a tsunami, and their ability to delay the arrival of the flooding water must be carefully balanced against the extra cost of the armour units.

In this respect, much research is still needed to ascertain the failure mechanism of armour units, and whether the placement of these armour units will increase the forces acting on the caissons behind them, especially if the armour units fail (Esteban at al., 2009). Also, it would be important to establish the failure mechanism of the breakwater against the outgoing wave, as this can generate strong currents that could displace the armour. As a tsunami event is made of more than one wave, it is important also 
that the structure can offer some protection against the second or third waves (that can sometimes be higher than the first)

This concept of differentiating between two types of tsunami levels is not without its problems, as it is often difficult to classify an event correctly, and the frequency and the height of an event might not match. A certain event might be level 2 for a certain area or country, yet only a level 1 event for others. For example, the March 2011 tsunami could be catalogued as a level 2 event in most of the areas it hit in Japan, though the waves that reached Chile would have been only a level 1 event. Exactly what tsunami wave height would constitute each of the levels would also depend on local geographical characteristics of the area. For the case of the Ria coastline in Tohoku, for example, many of the tsunami defences had been built with a $6-7 \mathrm{~m}$ tsunami wave height in mind, and it is clear that for that coastline a tsunami less than that height would have been a level 1 event. However, certain areas in Japan (such as the coast of Sanriku or parts of Iwate) appear to be often hit by large waves, and hence even large waves would only constitute a level 1 event due to the frequency with which they occur. Hence the classification of a level 1 or 2 event would be different even for the north or south parts of the Tohoku coastline. Nevertheless, this classification can often be heard at present within discussions of the Japanese Disaster Risk Management community.

It is also important to remember that the establishment of adequate level 2 tsunami heights is very difficult. To do so adequate historical records spanning millennia would be needed, though most countries' history is far shorter, and even when tsunamis are recorded in historic documents these do not usually show very detailed information (particularly for the case of the earlier documents). The field of paleotsunami can thus be very useful, though it often appears to be difficult to get reliable results as the top levels of the soil in urban areas can be disturbed by human activities, and these are the areas which are of greatest concern as they concentrate most of the population of coastal areas.

\section{CONCLUSIONS}

Following the 2011 Tohoku tsunami there is a general perception that tsunami counter-measures must be designed to fail in a non-catastrophic way, even if their design criteria is exceeded. Despite this, no formula has been developed in the past to design the armour of armour units against tsunami attack. The present research proposes a design formula based on laboratory experiments using solitary waves and field research of real life breakwater failures in the Tohoku region, which is shown to predict well the results measured in the lab and in the field. With regards to design, it is recommended that partial failure (equivalent to an $S$ value of 4) should be accepted when designing against the more extreme tsunami events (which are nowadays referred to in Japan as level 2 events). However, only limited damage (equivalent to an $S$ value of less than 2) should be required for the smaller and more frequent level 1 events.

Establishing what are the required tsunami inundation heights for level 1 and 2 events is notoriously difficult, and requires the study of ancient records and tsunami deposits. As most countries do not have records that span several millennia, and these records are often not detailed anyway, the study of tsunami deposits and seismic faults should be intensified to determine what are the worst events that can be expected in each region.

\section{ACKNOWLEDGMENTS}

The authors would like to acknowledge the kind financial contribution of the "Disaster Analysis and Proposal for Rehabilitation Process for the Tohoku Earthquake and Tsunami" Institute for Research on Reconstruction from the Great East Japan Earthquake/Composed Crisis Research Institute from Waseda University Research Initiatives. This contribution made possible some of the field visits on which some of this work rests.

\section{REFERENCES}

CERC. 1984 Shore Protection Manual. Co. Eng. Res. Center, U.S. Corps of Engineering, Vicksburg

Esteban, M., Takagi, H. and Shibayama, T. 2007. Improvement in Calculation of Resistance Force on Caisson Sliding due to Tilting. Coastal Engineering Journal (CEJ), Vol. 49, No.4 (2007) pp 417 441 
Esteban, M., Nguyen Danh Thao, Takagi, H. and Shibayama, T. 2009. Pressure Exerted by a Solitary Wave on the Rubble Mound Foundation of an Armoured Caisson Breakwater, 19 ${ }^{\text {th }}$ (2009) International Offshore and Polar Engineering Conference, Osaka.

Esteban, M., Takagi, H. and Shibayama, T. 2012. Modified Goda Formula to Simulate Sliding of Composite Caisson Breakwater, Coastal Engineering Journal, (under review)

Esteban M., Nguyen Danh Thao, Takagi H. and Shibayama T. 2008. Laboratory Experiments on the Sliding Failure of a Caisson Breakwater Subjected to Solitary Wave Attack. PACOMS-ISOPE Conference, Bangkok, Thailand.

Hudson, R.Y. 1959. Laboratory Investigation of Rubble-Mound Breakwaters, J. Waterways, Harbors Div., 85, ASCE, pp93-121.

Ikeno, M., Mori, N. and Tanaka, H. 2001. Experimental Study on Tsunami force and Impulsive Force by a Drifter under Breaking Bore like Tsunamis, Proceedings of Coastal Engineering, JSCE, Vol. 48, pp. 846-850.

Ikeno, M. and Tanaka, H. 2003. Experimental Study on Impulse Force of Drift Body and Tsunami Running up to Land, Proceedings of Coastal Engineering, JSCE, Vol. 50, pp. 721-725.

Kato, F., Suwa, Y., Watanabe, K., Hatogai, S. 2012. Mechanism of Coastal Dike Failure Induced by the Great East Japan Earthquake Tsunami. Proc. of 32nd Int. Conf. on Coastal Engineering (ICCE 2012) Santander, Spain.

Mikami, T., Shibayama, T., Esteban, M. and Matsumaru, R. 2012. Field Survey of the 2011 Tohoku Earthquake and Tsunami in Miyagi and Fukushima Prefectures, Coastal Engineering Journal $(C E J)$, Vol. 54, No. 1

Mizutani, S. and Imamura, F. 2000. Hydraulic Experimental Study on Wave Force of a Bore Acting on a Structure, Proceedings of Coastal Engineering, JSCE, Vol. 47, pp. 946-950.

Mori, N., Takahashi T. and The 2011 Tohoku Earthquake Tsunami Joint Survey Group. 2012 Nationwide survey of the 2011 Tohoku earthquake tsunami, Coastal Engineering Journal, Vol.54, Issue 1, pp.1-27.

Sakakiyama, T. 2012. Stability of Armour Units of Rubble Mound Breakwater Against Tsunamis. Proc. of 32nd Int. Conf. on Coastal Engineering (ICCE 2012) Santander, Spain.

Tanimoto, L., Tsuruya, K., and Nakano, S. 1984. Tsunami Force of Nihonkai-Chubu Earthquake in 1983 and Cause of Revetment Damage, Proceeding of the $31^{\text {st }}$ Japanese Conference on Coastal Engineering, JSCE.

Van der Meer, J. W. 1987. Stability of Breakwater Armour Layers. Coastal Engineering, Vol 11, p. 219-239. 